\title{
Ayak bileği kırıklarında sınıflama
}

\author{
Classification of ankle fractures
}

\author{
Serhan Ünlü, Önder Ersan
}

Dışkapı Yıldırım Beyazıt Eğitim ve Araştırma Hastanesi Ortopedi ve Travmatoloji Kliniği, Ankara

Ayak bilek kırıklarıyla sıklıkla karşılaşılmaktadır. Bu kırıkları sınıflamada en sık kullanılanlar Lauge-Hansen ve AO/ OTA sınıflamalarıdır. Lauge-Hansen sınıflaması ayağın pozisyonu ve ayağı etkileyen kuvvet göz önüne alınarak oluşturulmuştur. Kırığın tipiyle beraber, ayak bileği bağlarının durumu da bu sınıflamada önemlidir. Tekrarlanabilirliği ve akılda kalması zordur. AO/OTA sınıflaması radyolojik bir sınıflamadır; radyografide görülen kırık tipine ve kırığın sindezmoz seviyesiyle ilişkisine göre yapılmıştır; basit ve anlaşıırdır. Buna rağmen, her ikisinin de gözlemciler içi ve gözlemciler arası uygulanabilirliği varyasyonlar göstermektedir. Posterior ve mediyal malleolü değerlendirmede eksiklikleri olmasına rağmen, Weber sınıflaması hala klinik uygulamada sıklıkla kullanılmaktadır.

Anahtar sözcükler: ayak bileği; malleol kırıkları; sınıflandırma
Ankle fractures are increasingly common injuries in orthopaedic practice. These fractures are mostly classified with LaugeHansen and AO/OTA classifications. The Lauge-Hansen classification system was designed on the basis of foot position and the affecting force. In this classification system, ankle ligaments are also as important as fracture type. It is difficult to keep this classification in mind and repeatability is unsatisfactory. AO/OTA is a radiological classification system which is according to the type of fracture on X-ray and its relationship with syndesmosis. It is simple and easy to understand. However, both of these classifications have variable intra- and inter-observer reliabilities. Although Weber classification has deficiencies about posterior and medial malleolus evaluation, it is still widely used in clinical practice.

Key words: ankle; malleolar fractures; classification ınıflandırmalar kırı̆̆ı değerlendirmede, prognozunu belirlemede, klinik araştırmalarda ve literatürleri anlamada önemlidir. İdeal bir kırık sınıflaması kapsamlı ve kolay uygulanabilir olmalı, klinik tedavi ve prognoz hakkında bilgi vermelidir. Illk ayak bileği kırık sınıflaması Percival Pott tarafından tanımlanmış ve kırılan malleol sayısına göre unimalleolar, bimalleolar veya trimalleolar kırık olarak sınıflama yapılmıştır.. ${ }^{[1]}$ Daha sonra Niel Lauge-Hansen'in kadavra bacaklarına deforme edici kuvvetler uygulayarak tanımladığı sınıflandırma popüler olmuştur. ${ }^{[2]}$ Weber 1972'de başka bir sınıflandırma tanımlamıştır. 1979'da Arbeitsgemeinschaft für Osteosynthesefragen/ Orthopaedic Trauma Association (AO/OTA) sınıflaması geliştirilmiştir.

\section{LAUGE-HANSEN SINIFLAMASI}

Bu sınıflama ayak bileği kırıklarında en sık kullanılan sınıflamadır. ${ }^{[3]} \mathrm{Bu}$ sınıflamada ilk isim ayağın pozisyonunu (supinasyon veya pronasyon), sonraki adlandırma ise ayağa etkiyen kuvveti (eksternal rotasyon, abduksiyon veya adduksiyon) göstermektedir. Illk tanımlandığında dört kategori ve 13 alt gruptan oluşmaktadır. Daha sonra bu gruplara aksiyel yüklenme de dahil edilmiştir.

Supinasyon, ayak bileğinin tibia aksına göre iç rotasyonu, ayak önünün adduksiyonu, ayak arkasının inversiyonu hareketlerinin birleşiminden oluşmaktadır. Pronasyon ise; ayak bileğinin tibia aksına göre dış rotasyonu, ayak önünün abduksiyonu, ayak arkasının eversiyonu hareketlerinin birleşiminden oluşmaktadır.

\section{Supinasyon Eksternal Rotasyon Yaralanması}

En sık görülen Lauge-Hansen tipidir (\%40-75). Evre 1'de anterior inferior tibiofibular bağ (AITFB) yaralanır. Evre 2'de distal fibulada oblik veya spiral kırık oluşur. Evre 3'te posterior inferior tibiofibular bağ

- İletişim adresi: Op. Dr. Serhan Ünlü, Dışkapı Yıldırım Beyazıt Eğitim ve Araştırma Hastanesi, Ortopedi ve Travmatoloji Kliniği, İrfan Baştuğ Cad. Altındağ, Ankara Tel: 0532 - 4035002 e-posta: serhanunlu@yahoo.com

- Geliş tarihi: 3 Mayıs $2016 \quad$ Kabul tarihi: 3 Mayıs 2016 


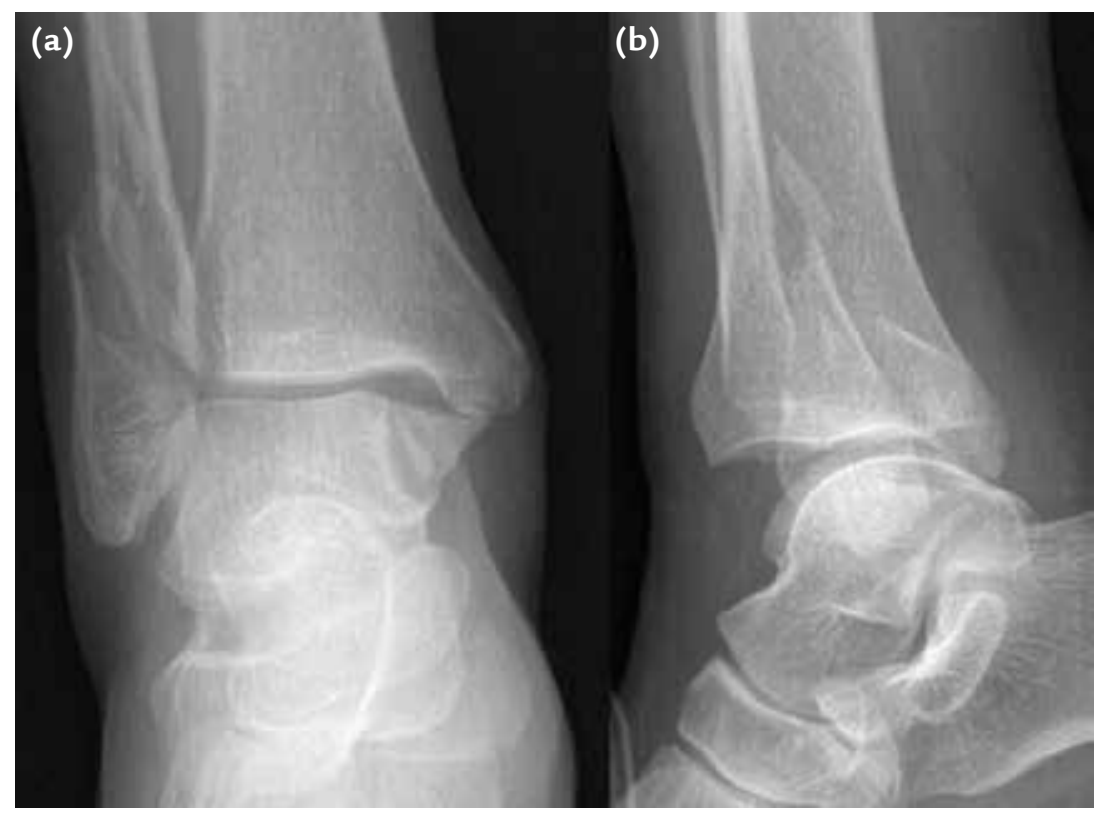

Şekil 1. a, b. Lauge-Hansen supinasyon eksternal rotasyon yaralanması.

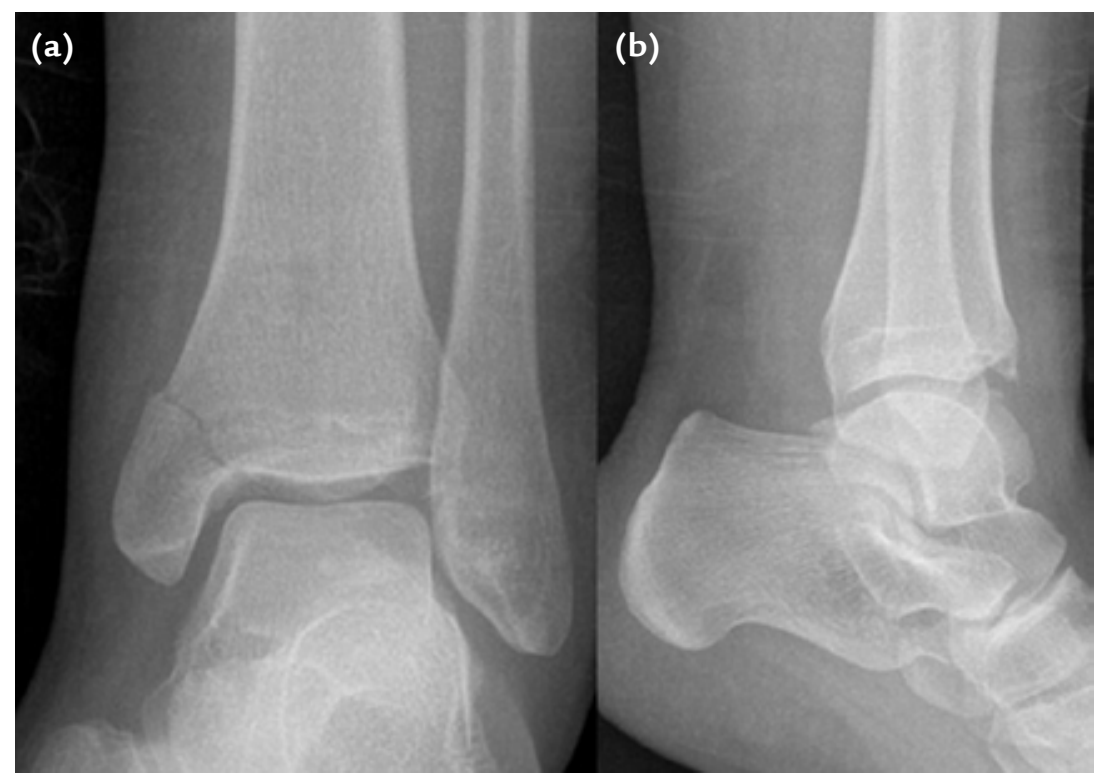

Şekil 2. a, b. Lauge-Hansen sınıflaması supinasyon adduksiyon yaralanması.

(PITFB) yırtılır veya posterior malleol kırı̆̆ı oluşur. Evre 4'te mediyal malleol kırı̆gı oluşur veya deltoid bağ yaralanır. Distal fibuladaki kırık anterior inferiordan başlar, posterior superior yönde uzanır. Ayak bileği yan radyografisinde daha iyi görülür. AiTFB tarafindan anterior tibial kenardan (Tillaux-Chaput) veya fibulanın anterior kenarından (LeFort-Wagstaffe) kopma kırığı oluşturabilir. PiTFB ise posterolateral tibial kopma kırığı (Volkmann üçgen parçası) yaratabilir (Şekil 1).

\section{Supinasyon Adduksiyon Yaralanması}

Malleol kırıklarının \%10-20'sini oluşturur. İki evre vardır. Evre 1'de ayak bileği eklem seviyesinin altında lateral malleolde transvers kırık oluşur. Evre 2'de mediyal malleolde vertikal kırık görülür (Şekil 2).

\section{Pronasyon Eksternal Rotasyon Yaralanması}

Görülme oranı \%7-20'dir. Evre 1'de deltoid bağ yırtığı veya mediyal malleol kopma kırı̆̆ı görülür. Evre 


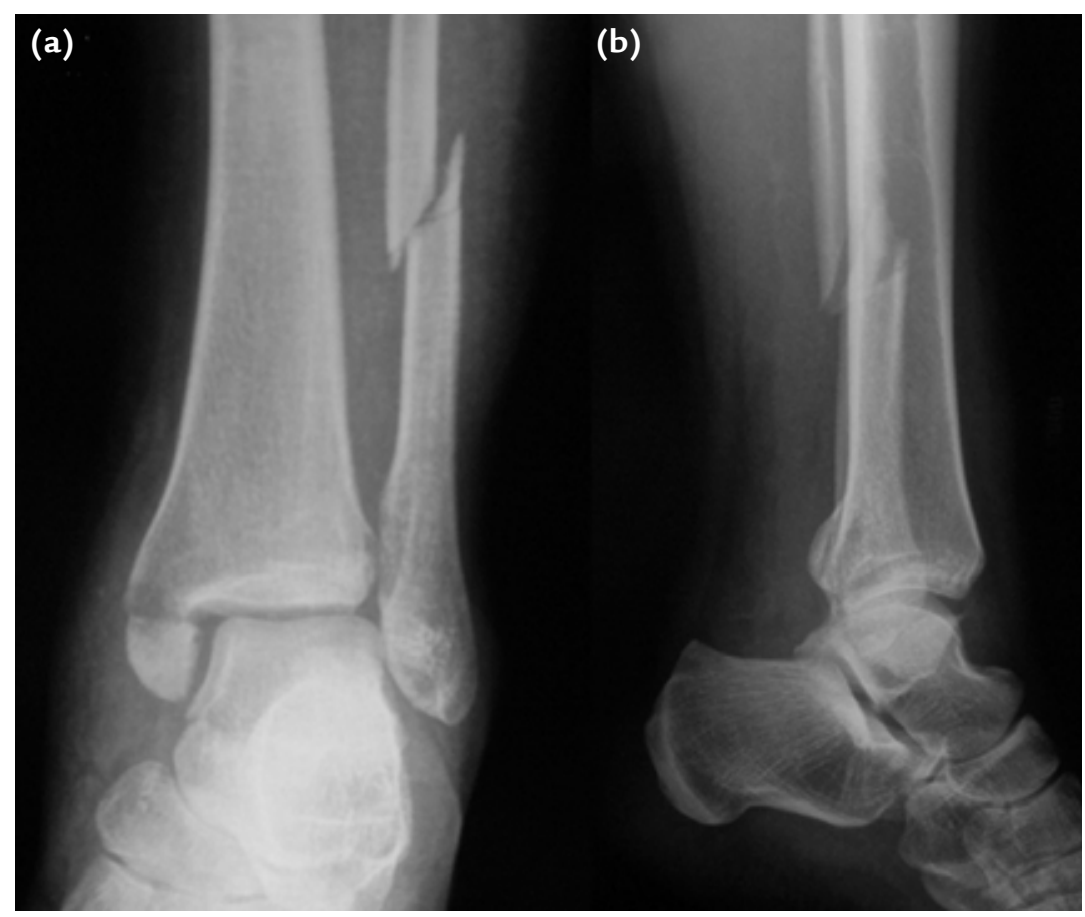

Şekil 3. a, b. Lauge-Hansen sınıflaması pronasyon eksternal rotasyon yaralanması.

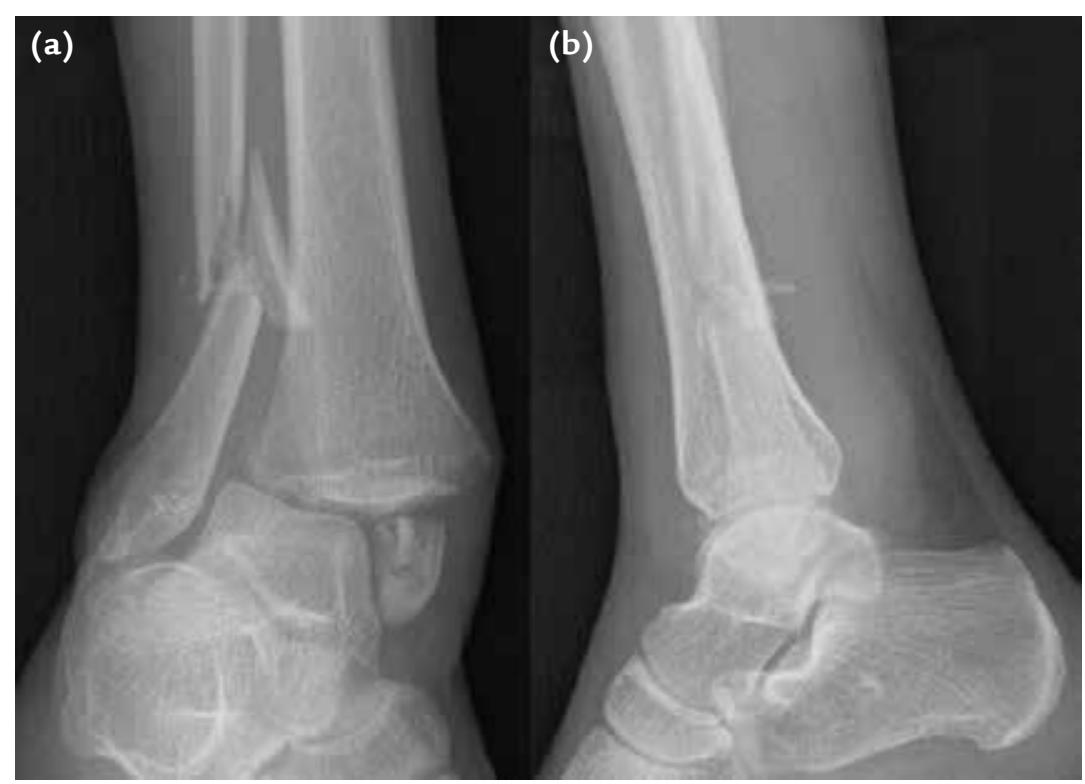

Şekil 4. a, b. Lauge-Hansen sınıflaması pronasyon abduksiyon yaralanması.

2'de AiTFB yaralanır. Evre 3'te ayak bileği eklem seviyesinin üzerinde oblik veya spiral fibula kırı̆̆ oluşur. Kırık tipik olarak proksimalde lateralden distalde mediyale doğru uzanır. Ayak bileği ön arka radyografisinde daha iyi görülür. Fibuladaki kırık bazen daha yukarı seviyede olabilir (Maisonneuve kırığı). Evre 4'te PITFB yaralanması veya posterior malleol kopma kırığı görülür (Şekil 3).

\section{Pronasyon Abduksiyon Yaralanması}

Tüm malleol kırıklarının \%5-20'sini oluşturur. Evre 1'de mediyal malleol kırı̆gı vardır. Evre 2'de AiTFB yırtığı oluşur. Evre 3'te ayak bileği eklem seviyesinin üzerinde transvers veya parçalı fibula kırığı meydana gelir (Şekil 4).

Lauge-Hansen sınıflaması çok kompleks ve zor bir sınıflamadır. Bu sınıflamanın gözlemci içi ve gözlemciler 
arası güvenilirliği ve tekrarlanabilirliği çok iyi değildir. Nielsen ve arkadaşlarının yaptığı çalışmada, 118 hastanın grafileri değerlendirilmiştir. Sadece grafilerin $\% 43$ 'ü tanımlanmıştır. Gözlemciler arası varyasyonu $\% 68$, gözlemci içi varyasyonu \%81-95 olarak bulunmuştur. ${ }^{[4]}$ Ayak bileğindeki kırığın oluş mekanizmasını açıkladığı için, redüksiyon sırasında yapılan manevrada yardımcı olur.

\section{DANIS-WEBER SINIFLAMASI}

Bu sınıflama, distal fibuladaki kırığın sindezmozla ilişkisine göre yapılan radyolojik bir sınıflamadır. [5,6] Tip A kırıkta; ayak bileği eklem seviyesinin altında transvers distal fibula kırı̆ı olur. Oblik veya vertikal mediyal malleol kırığı eşlik edebilir. Lauge-Hansen sınıflaması, supinasyon adduksiyon yaralanmasına benzerdir. Sindezmoz nadiren hasarlanır. Tip B kırıkta; ayak bileği eklem seviyesinde fibula kırı̆ıı vardır. Oblik veya spiral bir kırık proksimale doğru uzanabilir. Sindezmoz sıklıkla yaralanır. Lauge-Hansen sınıflaması supinasyon eksternal rotasyon yaralanmasına benzer bir yaralanmadır. Deltoid bağ yırtığı veya mediyal malleol kırığı eşlik edebilir. Tip C kırıkta; ayak bileği eklem seviyesinin yukarısında fibula kırığı vardır. Sıklıkla sindezmoz yaralanması eşlik eder. Lauge-Hansen sınıflaması pronasyon eksternal rotasyon ve pronasyon abduksiyon tipi yaralanmadır.

\section{AO/OTA SINIFLAMASI}

Tamamen radyolojik bir sınıflamadır. Basit ve kolay anlaşıırdır. Kırığın olduğu yere göre infra-sindezmotik, trans-sindezmotik ve supra-sindezmotik olmak üzere üçe ayrılır. Danis-Weber sınıflamasına benzemektedir. Mediyal veya posterior malleol kırığın olup olmamasına göre alt gruplara ayrılmaktadır (Tablo 1). ${ }^{[7]}$
Tablo 1. AO/OTA malleol kırık sınıflaması

$\begin{array}{ll}\text { 44-A1 } & \text { İzole lateral } \\ \text { 44-A2 } & \text { Lateral ve mediyal } \\ \text { 44-A3 } & \text { Lateral, mediyal ve posterior } \\ \text { 44-B1 } & \text { İzole lateral } \\ \text { 44-B2 } & \text { Lateral ve mediyal } \\ \text { 44-B3 } & \text { Lateral, mediyal ve Volkmann kırı̆̆ } \\ \text { 44-C1 } & \text { Basit diyafizyel } \\ \text { 44-C2 } & \text { Çok parçalı diyafizyel } \\ \text { 44-C3 } & \text { Proksimal fibula }\end{array}$

\section{SINIFLAMALARIN KARŞILAŞTIRILMASI}

Ayak bileğindeki kırık tipine göre sınıflamaların özeti Tablo 2'de verilmiştir. Hem AO/OTA sınıflaması hem de Lauge-Hansen sınıflaması, geniş kapsamlı sınıflamalar olmalarına rağmen ayak bileği kırıklarının yaklaşık \%10’luk bir bölümünü içermemektedir. Bir çalışmada, 300 ayak bileği kırı̆̆ı hastasında Lauge-Hansen sınıflaması kullanılmış; \%77 supinasyon eksternal rotasyon, \%13 pronasyon eksternal rotasyon, $\% 4$ supinasyon adduksiyon, $<\% 1$ pronasyon abduksiyon yaralanması tespit edilmiş, \%6 hastada ise kırık sınıflandırılamamıştır. ${ }^{[8]}$ Başka bir çalışmada, Lauge-Hansen sınıflaması ile \%10, AO sınıflaması ile \%8,7 kırık herhangi bir gruba dahil edilememiştir. ${ }^{[9]}$ Her iki sınıflamanın gözlemciler arası güvenilirlik ve tekrarlanabilirlik oranlarına bakıldığında, $A O$ sınıflaması Lauge-Hansen sınıflamasına göre daha iyi bulunmuştur. ${ }^{[10]}$

Tablo 2. Ayak bileği kırıklarında sınıflamaların karşılaştırılması

\begin{tabular}{lll}
\hline Kırık tipi & Lauge-Hansen & AO/OTA \\
\hline Sindezmoz seviyesinin altında transvers fibula kırığı & Supinasyon adduksiyon & Tip A \\
Vertikal mediyal malleol kırı̆̆ı & Supinasyon adduksiyon & Tip A \\
Kısa oblik sindezmoz seviyesinde fibula kırı̆̆ı & Supinasyon eksternal rotasyon & Tip B \\
Sindezmoz seviyesinin üstünde parçalı fibula kırığı & Pronasyon abduksiyon & Tip C \\
Sindezmoz seviyesinin üstünde oblik fibula kırı̆̆ı & Pronasyon eksternal rotasyon & Tip C
\end{tabular}




\section{KAYNAKLAR}

1. Pott P. Some few general remarks on fractures and dislocations. 1758. Clin Orthop Relat Res 2007;458:40-1.

2. Lauge-Hansen N. Fractures of the ankle: II. Combined experimental-surgical and experimental-roentgenologic investigations. Arch Surg 1950;60(5):957-85.

3. Tartaglione JP, Rosenbaum AJ, Abousayed M, DiPreta JA. Classifications in Brief: Lauge-Hansen Classification of Ankle Fractures. Clin Orthop Relat Res 2015;473(10):3323-8. Crossref

4. Nielsen JO, Dons-Jensen H, Sorensen HT. Lauge-Hansen classification of malleol fractures. An assessment of the reproducibility in 118 cases. Acta Orthop Scand 1990;61(5):385-7.

5. Danis R. Les fractures malleolaires. In: Danis R, editor. Theorie et Pratique de l'Osteosynthese. Paris, France; Masson \& Cie; 1949. p.133-65.
6. Weber BG. Die Verletzungen des oberen Sprunggelenkes, 2nd ed. Berne, Switzerland: Verlag Hans Huber; 1972.

7. Muller ME, Nazarian S, Koch P, Schatzker J. Tibia/Fibula. The Comprehensive Classification of Fractures of Long Bones. Berlin, Germany: Springer-Verlag; 1990. p.148-91.

8. Warner SJ, Garner MR, Hinds RM, Helfet DL, Lorich DG. Correlation Between the Lauge-Hansen Classification and Ligament Injuries in Ankle Fractures. J Orthop Trauma 2015;29(12):574-8. Crossref

9. Alexandropoulos C, Tsourvakas S, Papachristos J, Tselios A, Soukouli P. Ankle fracture classification: an evaluation of three classification systems: Lauge-Hansen, A. O. and BroosBisschop. Acta Orthop Belg 2010;76(4):521-5.

10. Yin MC, Yuan XF, Ma JM, Xia $Y$, Wang T, Xu XL, Yan YJ, Xu JH, Ye J, Tong ZY, Feng YQ, Wang HB, Wu XQ, Mo W. Evaluating the Reliability and Reproducibility of the $A O$ and LaugeHansen Classification Systems for Ankle İnjuries. Orthopedics 2015;38(7):e626-30. Crossref 